Jawwad Noor

\title{
Contemporary Neoclassicism and its Methodology
}

\section{Jawwad Noor*}

\begin{abstract}
The last 10 to 20 years have seen a rapid rise of a new school in Macroeconomics. One of the most interesting characteristics of this school is its use of non-econometric methods for predicting and calculating various variables of the economy. If traditional econometrics has lost some of the force it has had for decades, it is of interest to analyse the merits of the new system replacing it. Most importantly, it is of interest to study the methodological justification of this new system and the paradigm it rests on. The latter is the main purpose of this paper.
\end{abstract}

Today, the world of macroeconomics is characterised by two schools of thought, namely the Fresh Water Schools and the Salt Water Schools. The FW schools are those that follow Lucas-style neoclassical growth theory, downplay the use of econometrics in favour of what is known as calibration and numerical methods, and are proponents of the ideas of frictionless markets and rational expectations. These include schools like the University of Chicago, Minnesota, Pennsylvania and Rochester. The SW schools are relatively Keynesian in their approach towards the market and depend heavily on econometrics. Such schools include Harvard, MIT, UCLA, Princeton, etc. The purpose of this essay is to introduce to the reader the idea of calibration used by the FW schools, and to analyse its methodology.

\section{The Paradigm}

It is not possible to begin talking about calibration without first introducing the paradigm employed by the FW school. What shall be presented in this section is a simple exposition of the neoclassical growth mode1, as developed in the revolutionary work "Recursive Methods in Economic Dynamics" by Stokey, Lucas and Prescott (Harvard University Press, 1989), the bible of the FW schools.

The assumptions are:

\footnotetext{
* The author is currently doing his Ph.D. at the University of Rochester, New York State and is also a Visiting Lecturer at the Lahore School of Economics.
} 
1. The economy is inhabited by a single representative agent, who is infinitely-lived, and has a time additive utility function. For simplicity assume that he does not value leisure. Hence his utility function is given by $\underline{U}=\sum t \in[0, \infty](\beta \wedge t) U(c(t))$, where $\underline{U}$ is the lifetime utility, the summation is from $\mathrm{t}=0$ to $\mathrm{t}=\infty, \beta$ is the discount factor such that $0<\beta<1, \mathrm{U}$ is an a temporal utility function $\mathrm{U}: \mathrm{R}+\rightarrow$ $\mathrm{R}+$, and $\mathrm{c}(\mathrm{t})$ is consumption at time $\mathrm{t}$. It is assumed that $\mathrm{U}$ is increasing in its argument, concave, bounded, $\mathrm{U}(0)=0, \partial \mathrm{U} / \partial \mathrm{c}=\infty$ when $\mathrm{c}=0$.

2. There is a representative firm doing all the production in the economy: $\mathrm{Y}(\mathrm{t})=\mathrm{z}(\mathrm{t}) \cdot \mathrm{F}(\mathrm{K}(\mathrm{t}), \mathrm{L}(\mathrm{t}))$, such that $\mathrm{Y}(\mathrm{t})$ is the output at time $\mathrm{t}$ (we assume a one-sector economy), $z(t)$ is the technology coefficient at time $\mathrm{t}, \mathrm{F}$ is a function $\mathrm{F}: \mathrm{R}+\mathrm{x} \mathrm{R}+\rightarrow \mathrm{R}+$, and $\mathrm{K}(\mathrm{t}), \mathrm{L}(\mathrm{t})$ are capital and labour inputs at time $t$, respectively. It is assumed that the production function exhibits constant returns to scale, is concave, $\mathrm{F}(0,)=$.0 , and $\partial \mathrm{F} / \partial \mathrm{K}=\infty$ when $\mathrm{K}=0$. For simplicity we will assume a non-stochastic economy, i.e., $\mathrm{z}(\mathrm{t})=\mathrm{z} \forall \mathrm{t}$. Let $0<\mathrm{L}<1$.

3. The law of motion of capital is given by the expression: $K(t+1)=i(t)$ $+(1-d) K(t)$, where $i(t)$ is investment at time $t$, and $d$ is the (time invariant) depreciation rate such that $0 \leq \mathrm{d} \leq 1$.

4. The economy's resource constraint is $\mathrm{c}(\mathrm{t})+\mathrm{i}(\mathrm{t}) \leq \mathrm{Y}(\mathrm{t})$

The above assumptions paint a picture of an economy that has a single consumer, who owns the factors of production, and must decide (today) how to allocate resources between consumption and investment in each period. This formulation is called the Planner's problem, for obvious reasons. Since the representative consumer is understood to be a utility maximiser, he will solve the following Sequential Problem:

motion of capital

Maximize $\underline{U}$ subject to the resource constraint and the law of $\Rightarrow \operatorname{Max} \quad X=\sum t \in[0, \infty] \quad[(\beta \wedge t) U(c(t))-\lambda(t) \quad(c(t)+i(t)-$ $\mathrm{ZF}(\mathrm{K}(\mathrm{t}), \mathrm{L}(\mathrm{t})))-\mu(\mathrm{t})(\mathrm{K}(\mathrm{t}+1)-\mathrm{i}(\mathrm{t})-(1-\mathrm{d}) \mathrm{K}(\mathrm{t}))-\gamma(\mathrm{t})(1-\mathrm{L}(\mathrm{t}))]$, where $\lambda(\mathrm{t}), \mu(\mathrm{t})$ and $\gamma(\mathrm{t})$ are the kuhn-tucker multipliers.

$\Rightarrow \operatorname{Max} \quad \mathrm{X}=\sum \mathrm{t} \in[0, \infty][(\beta \wedge \mathrm{t}) \mathrm{U}(\mathrm{c}(\mathrm{t}))-\lambda(\mathrm{t})(\mathrm{c}(\mathrm{t})+\mathrm{K}(\mathrm{t}+1)-(1-$ d) $K(t)-Z F(K(t), L(t)))-\gamma(t)(1-L(t))]$ 
$\partial \mathrm{X} / \partial \mathrm{L}(\mathrm{t})=0$ will yield $\mathrm{us}$ the result that $\mathrm{L}(\mathrm{t})=1 \forall \mathrm{t}$ : since leisure is not valued, and more the leisure more the output, it follows that the consumer must give his maximum labor, ie $\mathrm{L}(\mathrm{t})=1$. So we can re-write the problem as follows:

$\operatorname{Max} X=\sum t \in[0, \infty][(\beta \wedge t) U(c(t))-\lambda(t)(c(t)+K(t+1)-(1-d) K(t)-$ $\mathrm{ZF}(\mathrm{K}(\mathrm{t}), 1))]$, where the only choice variables are $\mathrm{c}(\mathrm{t})$ and $\mathrm{K}(\mathrm{t}+1)$.

$\partial \mathrm{X} / \partial \mathrm{c}(\mathrm{t})=(\beta \wedge \mathrm{t}) \mathrm{U}^{\prime}(\mathrm{c}(\mathrm{t}))-\lambda(\mathrm{t})=0$

$\Rightarrow \lambda(\mathrm{t})=(\beta \wedge \mathrm{t}) \mathrm{U}^{\prime}(\mathrm{c}(\mathrm{t}))$

$\partial \mathrm{X} / \partial \mathrm{K}(\mathrm{t}+1)=-\lambda(\mathrm{t})+\lambda(\mathrm{t}+1)((1-\mathrm{d})+\mathrm{ZF}(\mathrm{K}(\mathrm{t}+1), 1))=0$

$\Rightarrow \lambda(t)=\lambda(t+1)\left((1-d)+Z F^{\prime}(K(t+1), 1)\right)$

from (1) we get

$$
\begin{aligned}
& \Rightarrow(\beta \wedge t) U^{\prime}(\mathrm{c}(\mathrm{t}))=(\beta \wedge \mathrm{t}+1) \mathrm{U}^{\prime}(\mathrm{c}(\mathrm{t}+1))((1-\mathrm{d})+\mathrm{ZF}(\mathrm{K}(\mathrm{t}+1), 1)) \\
& \Rightarrow \mathrm{U}^{\prime}(\mathrm{c}(\mathrm{t}))=\beta . \mathrm{U}^{\prime}(\mathrm{c}(\mathrm{t}+1))((1-\mathrm{d})+\mathrm{ZF}(\mathrm{K}(\mathrm{t}+1), 1))
\end{aligned}
$$

Equation (2) gives us a very important condition required to determine the optimal consumption in each time period. It is called the Euler equation. Intuitively it is telling us that the marginal benefit of a unit of consumption (given by the LHS of the equation) must be equal to the marginal cost (give by the RHS). But (almost) more importantly it is giving us a relationship that governs the dynamics of the economy. The Euler equation links each time period with each other. At any point in time, the representative consumer has effectively decided how much to consume and save today, tomorrow, the day after, ad infinitum.

The above was a simple demonstration of what the growth model is all about. It was an introduction to the framework used by macroeconomists of the school to model a large number of macro-phenomenon, e.g. growth, business cycles, inequality, distorted economies, unemployment, asset pricing, international finance, etc. Using the basic concepts, the macroeconomist has at his disposal well defined relationships between various variables in the economy. These relationships fully characterise the model economy, and it is this fact that is exploited in order to come up with an alternative to prediction via econometrics.

\section{Dynamic Programming}

One of the main contributions of Stokey, Lucas and Prescott was to show how such models as the one outlined in the previous section can be 
solved using dynamic programming methods. One of the advantages of employing dynamic programming is that it brings out yet more relationships characterising the economy. A discussion of this point is called for.

Stokey, Lucas and Prescott showed that to any sequential problem (such as the one outlined above) there corresponds a dynamic programming problem, if we make an extra (but innocuous) assumption. But what is a dynamic programming problem?

Observe that:

$$
\begin{aligned}
& \underline{\mathrm{U}(0)}=\sum \mathrm{t} \in[0, \infty](\beta \wedge \mathrm{t}) \mathrm{U}(\mathrm{c}(\mathrm{t})) \\
& =\mathrm{U}(\mathrm{c}(0))+\beta \mathrm{U}(\mathrm{c}(1))+\beta \wedge 2 . \mathrm{U}(\mathrm{c}(2))+\beta \wedge 3 . \mathrm{U}(\mathrm{c}(3))+\ldots . . \\
& =\mathrm{U}(\mathrm{c}(0))+\beta[\mathrm{U}(\mathrm{c}(1))+\beta . \mathrm{U}(\mathrm{c}(2))+\beta \wedge 2 . \mathrm{U}(\mathrm{c}(3))+\ldots . .] \\
& =\mathrm{U}(\mathrm{c}(0))+\beta \sum \mathrm{t} \in[1, \infty](\beta \wedge \mathrm{t}) \mathrm{U}(\mathrm{c}(\mathrm{t})) \\
& =\mathrm{U}(\mathrm{c}(0))+\beta . \underline{\mathrm{U}(1)}
\end{aligned}
$$

where, by similar argument, $\underline{\mathrm{U}(1)}=\mathrm{U}(\mathrm{c}(1))+\beta . \underline{\mathrm{U}(2)}$, so on and so forth.

That is, the lifetime utility function is broken down into two components: today's utility, and the utility for the remainder of my life, where the latter can be broken in a similar way. What this does is that it allows us to transform the problem from one in which we solve my lifetime problem in one go (the sequential problem) into one in which we separate today's problem from tomorrow's. This latter form (which is the dynamic programming problem) is extremely powerful: the assumption of an infinite life implies that today's problem is identical in structure to tomorrow's problem. So if we can establish a rule that will determine how today's problem can be solved, we have in effect established a rule that will determine how tomorrow's problem can be solved as well. In fact, this 'decision rule' arrived at can be used to solve any period's problem.

In order to elucidate the importance of this, let us first deviate a bit with some new terminology. A 'state' variable is a variable that cannot be changed (i.e. it is not a choice variable), and which determines one's choices. So, in the model outlined above, the state variable is the present capital stock $\mathrm{K}(\mathrm{t})$. Today's capital stock was chosen yesterday when the consumer decided how much to invest. The consumer cannot affect today's capital stock. Also, his present stock of capital is instrumental for deciding how much to consume today, and how much to save/invest: his total output $\mathrm{Y}(\mathrm{t})$ is determined by the value of $\mathrm{K}(\mathrm{t})$ (and also $\mathrm{L}(\mathrm{t})$, but recall that $\mathrm{L}(\mathrm{t})=1$ 
for all t), and it is this total output which he is going to divide into consumption and saving. Hence $K(t)$ affects his choice of how much he should consume today $c(t)$, and how much he must invest $i(t)$. Once he has decided how much to invest, he has in effect determined the value of $K(t+1)$, ie the value of the state variable tomorrow.

To emphasise the relevance of the state variable in decision-making we can write equation (3) as follows:

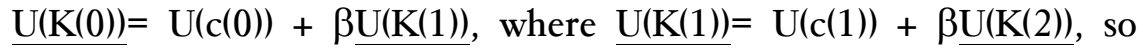
on and so forth.

Or more generally and compactly

$$
\underline{\mathrm{U}(\mathrm{K}(\mathrm{t}))}=\mathrm{U}(\mathrm{c}(\mathrm{t}))+\beta \underline{\mathrm{U}(\mathrm{K}(\mathrm{t}+1))}
$$

Now, maximising (4) subject to the resource constraint and the law of motion of capital will yield a certain optimal solution for the value of $\mathrm{c}(\mathrm{t})$ (and $K(t+1)$ of course). For any given value of $K(t)$, there will be an optimal $\mathrm{c}(\mathrm{t})$. In fact, it can be shown that under fairly general assumptions, there actually exists a function $\Gamma: \mathrm{R}+\rightarrow \mathrm{R}+$ which captures the relationship $\mathrm{c}(\mathrm{t})=\Gamma(\mathrm{K}(\mathrm{t}))$. Moreover, as before, the assumption of an infinite time horizon can be used to prove that this same function holds for any time period. That is to say, the function $\Gamma$ holds for time $t+1, t+2$, ad infinitum. We have what is called a decision rule; a rule that tells us that if the state variable takes so and so value, then the optimal consumption decision will be so and so value, regardless of what period we are in.

Why is this important? Simply because the macroeconomist has at his disposal yet one more relationship characterising the economy (actually he has a well-defined function). This function is important also because it will help the economist to predict how any economy will decide its consumption level when its capital stock changes, or how the economy would have acted if the capital stock had been any different. Note that the consumption decision rule is just one possible decision rule. If we expand the model to include more choice variables, we have a separate decision rule for each choice variable.

\section{Calibration}

We can now begin to talk about what calibration is. The discussion in the above two sections brought out the fact that the neoclassical growth model helps give rise to a handful of economic relationships that fully characterise the model economy. These equations will have variables and 
parameters. For instance, the Euler equation has $\mathrm{c}(\mathrm{t}), \mathrm{c}(\mathrm{t}+1), \mathrm{K}(\mathrm{t}+1)$ as its variables and $\beta$ and $\mathrm{d}$ as its parameters. If estimates of the parameters are found, then we have a set of equations that is all set to make predictions about the model economy. All that is needed is to plug in values of variables that we do know, and out come values of variables that we may not know. For instance, if we have figures for $K(t+1)$ (i.e. if we know $K(t)$ and $i(t)$ ), then we can predict next year's consumption $c(t+1)$ by using the consumption decision rule.

This is calibration. There is no regression line required to predict next years GNP or employment levels. The predictions are non-econometric in nature.

I do not wish to make it look as though econometrics is a redundant subject, or that statistical data is any less important. Indeed it is not. Estimating the parameters of the model is an econometric exercise. Time series data is needed in order to work out the functional forms of the relationships. Econometrics remains a backbone of the applied fields.

There are a lot more things that one can do using calibration than one could with econometrics. Calibration is not useful only in studying the future. Rather it has a tremendous amount of utility in studying and analysing the past. A classic example of this is "The Role of InvestmentSpecific Technological Change in the Business Cycle" by Krussel, Greenwood, and Hercowitz (European Economic Review, 2000) who construct a model of the US economy for the purpose of assessing how much the growth of investment-specific capital goods have contributed to over all US growth in the past. Such an exercise would not have been reliably possible without calibration. How would one separate the effect of different kinds of capital goods on US growth? How can one account for changes in the quality and variety of such goods over the decades when no reliable indices exist? With calibration the important relationships can be identified, and by plugging in the relevant figures, the desired figures can be obtained (for details see the paper).

The neoclassical growth model has had a great deal of success, which is the obvious reason why it has gained a tremendous amount of support over the years. But as is the case with all models in economics, it is not perfect. In some cases it may not find empirical support, or its implications may contradict data: blatant contradictions are embodied in the 'equity premium' puzzle and the 'risk free rate' puzzle. But these inconsistencies with the data are understood to ask for improvements in the standard model (like finding new functional forms for the utility 
Jawwad Noor 39

function) rather than to be complete falsifiers of the neoclassical paradigm.

\section{Methodology}

It is the foundations of any subject that is always less solid than its contents, except, perhaps, mathematics. Controversy over methodology is common in the social sciences. The methodology of the FW schools is no exception: calibration has some discomforting aspects.

Firstly, the results are extremely sensitive to the specification of the model. It is possible to reach a different conclusion about the value of a certain variable solely because it is the economist's discretion as to how he wants to specify the economy. For instance, does one want to use a CRRA utility function or an Epstein-Zin utility function, does one want to assume that government expenditure is completely unproductive, does one use a Cobb-Douglas production function, how many sectors must the economy have, etc, etc. Each specification will lead to a different result, and there is no a priori reason for believing that one specification will necessarily be superior to another.

Secondly, the method of computation will affect results. There are many computational techniques one can use to, for instance, work out an economy's decision rule for savings. There is value function iteration, policy function iteration, parametrisation of the value function, Coleman's algorithm, discrete state space method, etc.

Thirdly, how 'literally' is a model to be interpreted before it is calibrated? For instance, Lucas's asset pricing model ("Asset Prices in an Exchange Economy", Econometrica, 1978) assumes an endowment economy with no opportunities to save/invest or borrow/lend. Therefore the income is necessarily the same as consumption (assuming rationality). Now, when this model is calibrated to calculate the risk free interest rate of the US economy, do we use consumption figures for $\mathrm{c}(\mathrm{t})$ in the model or do we use national income? In the original model it does not matter since they are both equal. But in real life there is a significant difference between the two. One can argue that on principle one should use income, since it is only in place of income that $\mathrm{c}(\mathrm{t})$ enters the asset price equation. But then on the other hand one can argue that the model dictates that asset price function has consumption as its argument and not income. Do we take the model literally or do we adjust it for the non-realism of its assumptions?

These objections cannot be regarded as extremely serious for the simple reason that the existing alternatives to calibration have equally 
objectionable demerits. There is no clear superior, and hence one cannot afford to reject a system on the basis of its demerits. After all, econometric modeling also suffers from the first and third criticism outlined above, and the second criticism cannot be taken too seriously since numerical methods do not systematically yield divergent results.

More criticism of calibration arises out of the criticism of the neoclassical growth model itself. These include an attack on the assumptions of the neoclassical growth model. Specifically, it is argued that a model based on the utility maximisation of an imaginary representative consumer is too far-fetched to be taken seriously. The representative agent does not capture the complex workings of a society consisting of many agents, each with his own agenda often conflicting with that of others.

Such objections are raised all the time, but this seems to reflect a basic lack of understanding of economic and scientific methodology more than anything else. If the main aim of any science (and social science) is to predict, then what is of primary importance is the predictive power of any model, even if the model rests on unrealistic assumptions. This is the point made in "The Methodology of Positive Economics" by Friedman (Essays in Positive Economics, University of Chicago Press, 1953). Another way to reach this same result is through Karl Popper's theory of demarcation, a theory generally accepted in the natural sciences. According to Popper, any theory that has testable implications (i.e. it is falsifiable) is considered scientific. On testing these implications, either one falsifies the theory, or fails to falsify it (one can never verify a theory), and in the case of the latter one accepts the theory until some further evidence comes to falsify it. Note that the assumptions of the theory are not the issue at all. The neoclassical growth model is a falsifiable theory, one that has been seen to fare favorably with the data (the standards of social sciences are relatively lower than that of the physical sciences, and hence a theory in social sciences is deemed as being supported by the data even if there are numerous instances of its being rejected by the data). Since it has fared well empirically the model is accepted, along with its unrealistic assumptions.

Realism of the model is just subordinated to the more pragmatic need of predictive power. It is not unimportant. In fact, of two theories, each equally powerful as predictors, the more realistic is regarded as superior. One can see this very clearly in choice theory, where the homoeconomicus is relieved of his requirement of being able to measure utility (classical marginal utility theory) and to merely be able to rank choices (revealed preference theory). The movement is governed by the need for more acceptable and descriptively accurate axioms. One can interpret the birth of the representative agent assumption in neoclassical growth theory in 
the same way. The neoclassical growth paradigm gave formal microeconomic foundations to a macroeconomics that had no such foundations (the Keynesian IS-LM-AD-AS model is an example). It is better to have a bad model capturing the fact that hoards of individuals make choices in the economy rather than have none at all.

I would like to conclude the discussion with a comment. The legitimacy of calibration is critically dependent on the truth of the neoclassical growth paradigm. It is crucial that the economy behave (at least approximately) as if it were inhabited by a single consumer who chose all the macroeconomic variables in a way so as to maximise his utility. If this model is a good approximation, then one is justified to stretch calibration in to areas where traditional estimation techniques would become unreliable. Data speaks nothing more than what it is. Yet through calibration one can make the data speak more than what it is, since this data can be used to construct equations that govern the relationships between all variables, and then these equations help us make more statements than what the data itself is making. All these extra statements rest solely on the basic paradigm.

In a word, rendering the paradigm false is to render calibration baseless. 
42 The Lahore Journal of Economics, Vol.6, No.2

\section{References}

Krussel, Greenwood, and Hercowitz, 2000, The Role of Investment-Specific Technological Change in the Business Cycle, European Economic Review.

M. Friedman, 1953, The Methodology of Positive Economics, Essays in Positive Economics, University of Chicago Press.

R. Lucas, 1978, Asset Prices in an Exchange Economy, Econometrica.

Stokey, Lucas and Prescott, 1989, Recursive Methods in Economic Dynamics, University Press. 